\title{
Fixed Point Theorems in S-Metric Spaces
}

\author{
K. Prudhvi \\ Department of Mathematics, University College of Science, Saifabad, Osmania University, Hyderabad, Telangana State, India
}

Copyright (C) 2015Horizon Research Publishing All rights reserved.

\begin{abstract}
In this paper, we prove two fixed point theorems in S-metric spaces. Our results extend and improve some known results.
\end{abstract}

Keywords S-metric Space, Fixed Point

2010 AMS Subject Classification: 54H25, 54E99

\section{Introduction and Preliminaries}

In 2006, Z. Mustafa and B.I. Sims [7] introduced the concept of G-metric space which is a generalization of metric space, and proved some fixed point theorems in G-metric spaces. After that, many authors have proved some fixed point theorems in these G- metric spaces (see, e.g. [3], [8], [12]). In 1992, B. C. Dhage [4] introduced the notion of D-metric space and proved some fixed point theorems. In 2007, S. Sedghi, N.Shobe and H. Zhou [11] introduced $\mathrm{D}^{*}$-metric spaces which is a modification of D-metric spaces of [4] and proved some fixed point theorems in $\mathrm{D}^{*}$-metric spaces. Later on many authors have studied the fixed point theorems in generalized metric spaces (see, e.g. $[1,5,6])$. In 2012, S. Sedghi et al. [10] introduced the notion of S-metric space which is a generalization of a G-metric space of [4] and $D^{*}$ - metric space of [11] and obtained some fixed point theorems on S-metric spaces. Recently, S.Sedghi and N.V.Dung [9] have proved some generalized fixed point theorems in S-metric spaces which are generalization of [10]. In this paper, we proved two fixed point results in S-metric spaces. Our results extend and improve the results of [9].

Definition 1.1.[2] Let $\mathrm{X}$ be a nonempty set. A metric on $\mathrm{X}$ is a function $\mathrm{d}: \mathrm{X}^{2} \rightarrow[0, \infty)$ if there exists a real number $\mathrm{b} \geq 1$ such that the following conditions holds for all $\mathrm{x}, \mathrm{y}, \mathrm{z} \in \mathrm{X}$.

(i) $d(x, y)=0$ if and only if $x=y$.

(ii) $\mathrm{d}(\mathrm{x}, \mathrm{y})=\mathrm{d}(\mathrm{y}, \mathrm{x})$.

(iii) $\mathrm{d}(\mathrm{x}, \quad \mathrm{z}) \leq \mathrm{b}[\mathrm{d}(\mathrm{x}, \mathrm{y})+\mathrm{d}(\mathrm{y}, \mathrm{z})]$.

The pair $(X, d)$ is called a $B$-metric space.

Definition 1.2. [10] Let $X$ be a nonempty set. An S-metric on $X$ is a function $S: X^{3} \rightarrow[0, \infty)$ that satisfies the following conditions holds for all $\mathrm{x}, \mathrm{y}, \mathrm{z}, \mathrm{a} \in \mathrm{X}$. (i) $S(x, y, z)=0$ if and only if $x=y=z$.

(ii) $\mathrm{S}(\mathrm{x}, \mathrm{y}, \mathrm{z}) \leq \mathrm{S}(\mathrm{x}, \mathrm{x}, \mathrm{a})+\mathrm{S}(\mathrm{y}, \mathrm{y}, \mathrm{a})+\mathrm{S}(\mathrm{z}, \mathrm{z}, \mathrm{a})$.

The pair $(X, S)$ is called an $S$-metric space.

Definition 1.3. [10] Let $(X, S)$ be an S-metric space. For $r>0$ and $x \in X$, we define the open ball $B_{S}(x, r)$ and the closed ball

$$
\begin{aligned}
& B_{S}[x, r] \text { with centre } x \text { and radius } r \text { as follows } \\
& B_{S}(x, r)=\{y \in X: S(y, y, x)<r\} \\
& B_{S}[x, r]=\{y \in X: S(y, y, x) \leq r\}
\end{aligned}
$$

The topology induced by the S-metric is the topology generated by the base of all open balls in $\mathrm{X}$.

Definition 1.4. [10] Let $(X, S)$ be an S-metric space.

(i)A sequence $\left\{x_{n}\right\} \subset X$ converges to $x \in X$ if $\mathrm{S}\left(\mathrm{x}_{\mathrm{n}}, \mathrm{x}_{\mathrm{n}}, \mathrm{x}\right) \rightarrow 0$ as $\mathrm{n} \rightarrow \infty$. That is, for each $\varepsilon>0$, there exists $\mathrm{n}_{0} \in \mathbb{N}$ such that

for all $n \geq n_{0}$ we have $S\left(x_{n}, x_{n}, x\right)<\varepsilon$. We write for $x_{n} \rightarrow x$.

(ii)A sequence $\left\{x_{n}\right\} \subset X$ is a Cauchy sequence if $\mathrm{S}\left(\mathrm{x}_{\mathrm{n}}, \mathrm{x}_{\mathrm{n}}, \mathrm{x}_{\mathrm{m}}\right) \rightarrow 0$ as $\mathrm{n}, \mathrm{m} \rightarrow \infty$. That is, for each $\varepsilon>0$, there exists $n_{0} \in \mathbb{N}$

such that for all $n, m \geq n_{0}$ we have $S\left(x_{n}, x_{n}, x_{m}\right)<\varepsilon$.

(iii) The S-metric space (X, S)is complete if every Cauchy sequence is a convergent.

Lemma 1.5.[10] In an $S$-metric space, we have $S(x, x, y)=$ $\mathrm{S}(\mathrm{y}, \mathrm{y}, \mathrm{x})$ for all $\mathrm{x}, \mathrm{y} \in \mathrm{X}$.

Lemma 1.6.[10] Let $(X, S)$ be an S-metric space. If $x_{n} \rightarrow x$ and $\mathrm{y}_{\mathrm{n}} \rightarrow \mathrm{y}$ then $\mathrm{S}\left(\mathrm{x}_{\mathrm{n}}, \mathrm{x}_{\mathrm{n}}, \mathrm{y}_{\mathrm{n}}\right) \rightarrow \mathrm{S}(\mathrm{x}, \mathrm{x}, \mathrm{y})$.

\section{Main Results}

In this section, we prove two fixed point theorems in Smetric spaces.

S. Sedghi, N.V. Dung [9] introduced an implicit relation to investigate some fixed point theorems on S-metric spaces.

Let $\boldsymbol{M}$ be the family of all continuous functions of five variables $M: \mathbb{R}_{+}{ }^{5} \rightarrow \mathbb{R}_{+}$. For some $k \in[0,1)$, we consider the following conditions. 
$\left(C_{1}\right)$ For all $x, y, z \in \mathbb{R}_{+}$, if $y \leq M(x, x, 0, z, y)$ with $\mathrm{z} \leq 2 \mathrm{x}+\mathrm{y}$, then $\mathrm{y} \leq \mathrm{kx}$.

$\left(C_{2}\right)$ For all $y \in \mathbb{R}_{+}$, if $y \leq M(y, 0, y, y, 0)$, then $y=0$.

$\left(C_{3}\right)$ If $x_{i} \leq y_{i}+z_{i}$ for all $x_{i}, y_{i}, z_{i} \in \mathbb{R}_{+}, i \leq 5$, then

$\mathrm{M}\left(\mathrm{x}_{1}, \mathrm{x}_{2}, \mathrm{x}_{3}, \mathrm{x}_{4}, \mathrm{x}_{5}\right) \leq \mathrm{M}\left(\mathrm{y}_{1}, \mathrm{y}_{2}, \mathrm{y}_{3}, \mathrm{y}_{4}, \mathrm{y}_{5}\right)+\mathrm{M}\left(\mathrm{z}_{1}, \mathrm{z}_{2}, \mathrm{z}_{3}, \mathrm{z}_{4}, \mathrm{z}_{5}\right)$.

Moreover, for all $\mathrm{y} \in \mathrm{X}, \mathrm{M}(0,0,0, \mathrm{y}, 2 \mathrm{y}) \leq \mathrm{ky}$.

Note: The coefficient $\mathrm{k}$ in conditions $\left(\mathrm{C}_{1}\right)$ and $\left(\mathrm{C}_{3}\right)$ may be different, for example, $\mathrm{k}=\mathrm{k}_{1}$ and $\mathrm{k}_{3}$ respectively. But we assume that they are equal by putting $\mathrm{k}=\max \left\{\mathrm{k}_{1}, \mathrm{k}_{3}\right\}$.

The following Theorem is proved in [9] (Theorem 2.6 [9]).

Theorem 2.1. (Theorem 2.6 [9]). Let $\mathrm{T}$ be a self-map on a complete S-metric space $(\mathrm{X}, \mathrm{S})$ and

$$
\begin{aligned}
& \mathrm{S}(\mathrm{Tx}, \mathrm{Tx}, \mathrm{Ty}) \leq \mathrm{M}(\mathrm{S}(\mathrm{x}, \mathrm{x}, \mathrm{y}), \mathrm{S}(\mathrm{Tx}, \mathrm{Tx}, \mathrm{x}), \mathrm{S}(\mathrm{Tx}, \mathrm{Tx}, \mathrm{y}), \\
& \mathrm{S}(\mathrm{Ty}, \mathrm{Ty}, \mathrm{x}), \mathrm{S}(\mathrm{Ty}, \mathrm{Ty}, \mathrm{y}))
\end{aligned}
$$

for all $\mathrm{x}, \mathrm{y}, \mathrm{z} \in \mathrm{X}$ and some $\mathrm{M} \in \mathcal{M}$. Then we have

(i) If $M$ satisfies the condition $\left(C_{1}\right)$, then $T$ has a fixed point. Moreover, for any $\mathrm{x}_{0} \in \mathrm{X}$ and the fixed point $\mathrm{x}$, we have

$$
\mathrm{S}\left(\mathrm{Tx}_{\mathrm{n}}, \mathrm{Tx}_{\mathrm{n}}, \mathrm{x}\right) \leq 2 \mathrm{k}^{\mathrm{n}} / 1-\mathrm{kS}\left(\mathrm{x}_{0}, \mathrm{x}_{0}, \mathrm{Tx}_{0}\right) .
$$

(ii) If $\mathrm{M}$ satisfies the condition $\left(\mathrm{C}_{2}\right)$ and $\mathrm{T}$ has a fixed point, then the fixed point is unique.

(iii) If $\mathrm{M}$ satisfies the condition $\left(\mathrm{C}_{3}\right)$ and $\mathrm{T}$ has a fixed point, then $\mathrm{T}$ is continuous at $\mathrm{X}$.

Theorem 2.2. Let $\mathrm{T}$ be a self-map on a complete S-metric space $(X, S)$ and

$\mathrm{S}(\mathrm{Tx}, \mathrm{Tx}, \mathrm{Ty}) \leq \mathrm{h} \max \{\mathrm{S}(\mathrm{x}, \mathrm{x}, \mathrm{y}), \mathrm{S}(\mathrm{Tx}, \mathrm{Tx}, \mathrm{x}), \mathrm{S}(\mathrm{Ty}, \mathrm{Ty}, \mathrm{y})\}$

for some $h \in[0,1)$ and for all $x, y \in X$. Then $T$ has a unique fixed point in $X$. Moreover, if $h \in[0,1 / 2)$, then $T$ is continuous at the fixed point.

Proof. The following ascertain is by using the above Theorem 2.1 withM(x, y, z, s, t $)=h \max \{x, y, t\}$ for some $h \in[0,1)$ and for all $x, y, z, s, t \in \mathbb{R}_{+}$. Indeed, $M$ is continuous. First, we have,

$$
\mathrm{M}(\mathrm{x}, \mathrm{x}, 0, \mathrm{z}, \mathrm{y})=\mathrm{h} \max \{\mathrm{x}, \mathrm{x}, \mathrm{y}\} .
$$

$$
\text { So, if } y \leq M(x, x, 0, z, y) \text { with } z \leq 2 x+y \text {, then }
$$

$$
\mathrm{y} \leq \mathrm{hx} \text { or } \mathrm{y} \leq \mathrm{hy} \text {. }
$$

Therefore, $\mathrm{y} \leq \mathrm{hx}$.

Therefore, $\mathrm{T}$ satisfies the condition $\left(\mathrm{C}_{1}\right)$.

If $\mathrm{y} \leq \mathrm{M}(\mathrm{y}, 0, \mathrm{y}, \mathrm{y}, 0)=\mathrm{h} \max \{\mathrm{y}, 0,0\}=\mathrm{hy}$, then $\mathrm{y}=0$. Since, $\mathrm{h}<1 / 2$.

Therefore, $\mathrm{T}$ satisfies the condition $\left(\mathrm{C}_{2}\right)$.

Finally, if $x_{i} \leq y_{i}+z_{i}$ for $i \leq 5$, then

$\mathrm{M}\left(\mathrm{x}_{1}, \mathrm{x}_{2}, \mathrm{x}_{3}, \mathrm{x}_{4}, \mathrm{x}_{5}\right)=\mathrm{h} \max \left\{\mathrm{x}_{1}, \mathrm{x}_{2}, \mathrm{x}_{5}\right\}$

$$
\begin{aligned}
& =\mathrm{h} \max \left\{\mathrm{y}_{1}+\mathrm{z}_{1}, \mathrm{y}_{2}+\mathrm{z}_{2}, \mathrm{y}_{5}+\mathrm{z}_{5}\right\} \\
& \leq \mathrm{h} \max \left\{\mathrm{y}_{1}, \mathrm{y}_{2}, \mathrm{y}_{5}\right\}+\mathrm{h} \max \left\{\mathrm{z}_{1}, \mathrm{z}_{2}, \mathrm{z}_{5}\right\}
\end{aligned}
$$

$$
=\mathrm{M}\left(\mathrm{y}_{1}, \mathrm{y}_{2}, \mathrm{y}_{3}, \mathrm{y}_{4}, \mathrm{y}_{5}\right)+\mathrm{M}\left(\mathrm{z}_{1}, \mathrm{z}_{2}, \mathrm{z}_{3}, \mathrm{z}_{4}, \mathrm{z}_{5}\right) .
$$

Moreover, $\mathrm{h} \in[0,1 / 2)$, then $2 \mathrm{~h}<1$ and

$\mathrm{M}(0,0,0, \mathrm{y}, 2 \mathrm{y})=\mathrm{h} \max \{0,2 \mathrm{y}\}$

$$
=2 \mathrm{hy} \text {, where } 2 \mathrm{~h}<1 \text {. }
$$

Therefore, $\mathrm{T}$ satisfies the condition $\left(\mathrm{C}_{3}\right)$.

Theorem 2.3. Let $\mathrm{T}$ be a self-map on a complete S-metric space $(X, S)$ and

$\mathrm{S}(\mathrm{Tx}, \mathrm{Tx}, \mathrm{Ty}) \leq \mathrm{h} \max \{\mathrm{S}(\mathrm{x}, \mathrm{x}, \mathrm{y}), \mathrm{S}(\mathrm{Tx}, \mathrm{Tx}, \mathrm{y}), \mathrm{S}(\mathrm{Ty}, \mathrm{Ty}, \mathrm{x})\}$ for some $h \in[0,1 / 3)$ and for all $x, y \in X$. Then $T$ has a unique fixed point in $\mathrm{X}$. Moreover, $\mathrm{T}$ is continuous at the fixed point.

Proof. The following ascertain is by using the above Theorem 2.1 withM $(x, y, z, s, t)=h \max \{x, z, s\}$ for some $h \in[0,1 / 3)$ and for all $x, y, z, s, t \in \mathbb{R}_{+}$. Indeed, $M$ is continuous. First, we have,

$$
\mathrm{M}(\mathrm{x}, \mathrm{x}, 0, \mathrm{z}, \mathrm{y})=\mathrm{h} \max \{\mathrm{x}, 0, \mathrm{z}\} .
$$

So, if $y \leq M(x, x, 0, z, y)$ with $z \leq 2 x+y$, then

$\mathrm{y} \leq \mathrm{hx}$ ory $\leq 2 \mathrm{hx}+\mathrm{hy}$. Then $\mathrm{y} \leq \mathrm{kx}$ with

$$
\mathrm{k}=\max \{\mathrm{h}, 2 \mathrm{~h} / 1-\mathrm{h}\}<1 \text {. }
$$

Therefore, $\mathrm{T}$ satisfies the condition $\left(\mathrm{C}_{1}\right)$.

Next, if $y \leq M(y, 0, y, y, 0)=h . y$, then $y=0$ since, $h<1 / 3$.

Therefore, $\mathrm{T}$ satisfies the condition $\left(\mathrm{C}_{2}\right)$.

Finally, if $x_{i} \leq y_{i}+z_{i}$ for $i \leq 5$, then

$$
\begin{aligned}
\mathrm{M}\left(\mathrm{x}_{1}, \mathrm{x}_{2}, \mathrm{x}_{3}, \mathrm{x}_{4}, \mathrm{x}_{5}\right) & =\mathrm{h} \max \left\{\mathrm{x}_{1}, \mathrm{x}_{3}, \mathrm{x}_{4}\right\} \\
& =\mathrm{h} \max \left\{\mathrm{y}_{1}+\mathrm{z}_{1}, \mathrm{y}_{3}+\mathrm{z}_{3}, \mathrm{y}_{4}+\mathrm{z}_{4}\right\} \\
& \leq \mathrm{h} \max \left\{\mathrm{y}_{1}, \mathrm{y}_{3}, \mathrm{y}_{4}\right\}+\mathrm{h} \max \left\{\mathrm{z}_{1}, \mathrm{z}_{3}, \mathrm{z}_{4}\right\} \\
& =\mathrm{M}\left(\mathrm{y}_{1}, \mathrm{y}_{2}, \mathrm{y}_{3}, \mathrm{y}_{4}, \mathrm{y}_{5}\right)+\mathrm{M}\left(\mathrm{z}_{1}, \mathrm{z}_{2}, \mathrm{z}_{3}, \mathrm{z}_{4}, \mathrm{z}_{5}\right) .
\end{aligned}
$$

Moreover, $h \in[0,1 / 2)$, then $2 h<1$ and

$$
\begin{aligned}
\mathrm{M}(0,0,0, \mathrm{y}, 2 \mathrm{y}) & =\mathrm{h} \max \{0,0, \mathrm{y}\} \\
& =\text { hy, where } \mathrm{h}<1 .
\end{aligned}
$$

Therefore, $\mathrm{T}$ satisfies the condition $\left(\mathrm{C}_{3}\right)$.

\section{REFERENCES}

[1] R. P. Agarwal, M.Meehan, D.O.Regan, Fixed Point Theory and Applications, Cambridge University Press, 2004.

[2] I. A. Bakhtin, The contraction principle in quasimetric spaces, Func. An., Ulianowsk, Gos.Ped.Ins.30(1989),26-37.

[3] R.Chugh, T.Kadian, A.Rani, B.E.Rhoades, Property $\mathrm{P}$ in G-metric spaces, Fixed Point Theory Appl. Vol.2010, Article ID 401684.

[4] B.C.Dhage, Generalized metric spaces mappings with fixed point, Bull. Calcutta Math.Soc.84(1992), 329-336.

[5] M. Jovanvić, Z. Kadelburg, S.Radenović, Common fixed point results in metric-type spaces, Fixed Point Theory Appl.2010(2012),1-15. 
[6] M.A.Khamsi, Remarks on cone metric spaces and fixed point theorems of contractive mappings, Fixed Point Theory Appl.2010(2010),1-7.

[7] Z. Mustafa, B. I. Sims, A new approach to generalized metric spaces, J. Nonlinear Convex Anal. 7(2006), 289-297.

[8] Z. Mustafa, H.Obiedat, F.Awawdeh, Some common fixed point theorems for mapping on complete G-metric spaces, Fixed Point Theory Appl. Vol.2008,Article ID 189870.

[9] S. Sedghi , N. V. Dung, Fixed point theorems on S-metric spaces, Mat. Vesnik 66,1(2014), 113-124.
[10] S. Sedghi, N. Shobe, A. Aliouche, A generalization of fixed point theorem in S-metric spaces, Mat. Vesnik 64(2012), 258-266.

[11] S. Sedghi, N. Shobe, H. Zhou, A common fixed point theorem in $\mathrm{D}^{*}$-metric space, Fixed Point Theory Appl. (2007), 1-13.

[12] W. Shatanawi, Fixed point theory for contractive mappings satisfying $\boldsymbol{\Phi}$ - maps in G-metric spaces, Fixed Point Theory Appl. (2010), Article ID 181650. 